\title{
NOTES
}

\section{Radical Ring-Opening Polymerization Behavior of Halogenated Phenyl-3-vinyloxiranes}

\author{
Toshio Kolzumi, ${ }^{* \dagger}$ Osamu MoriYa, ${ }^{*}$ Yoshikiyo Urata, ${ }^{*}$ \\ Yoshiaki NoJIMA, ${ }^{* *}$ and Takeshi Endo**, ${ }^{*}$ \\ * Department of Chemistry, The National Defense Academy, Hashirimizu, \\ Yokosuka 239, Japan \\ ** Research Laboratory of Resources Utilization, Tokyo Institute of Technology, \\ Nagatsuta-cho, Midori-ku, Yokohama 227, Japan
}

(Received December 28, 1994)

\begin{abstract}
KEY WORDS Radical Polymerization / Radical Ring-Opening Polymerization / Polymerization Behavior / Vinyloxirane / Halogenated Phenyl-3vinyloxirane /
\end{abstract}

Radical ring-opening polymerization is important for the synthesis of polymers having functional groups such as ester, ether, ketone, and carbonate in the main chain. ${ }^{1}$ Recently, we reported that $p$-substituted 2-phenyl-3vinyloxirane derivatives (1) underwent complete ring-opening polymerization via selective cleavage of the carbon-carbon bond of the oxirane ring to give the polymers bearing a vinyl ether moiety in the backbone (Scheme 1). ${ }^{2}$

Cho et al. reported that when the radical polymerization of 1a $(X=H)$ was carried out at $120^{\circ} \mathrm{C}$ in bulk, only a gelled polymer was obtained probably due to crosslinking on the vinyl ether group of the resulting polymer. ${ }^{3}$ On the other hand, we have found that 2-isopropenyl-3-phenyloxirane, which has a methyl group at the $\alpha$-position of the vinyl group of

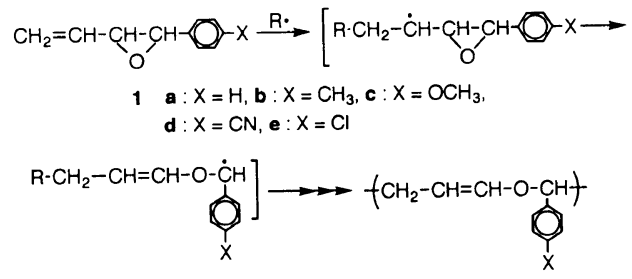

Scheme 1. 1a, cannot undergo crosslinking of the resulting polymer even by radical polymerization at $120^{\circ} \mathrm{C}$ in bulk because of the formation of a hindered olefin by the methyl group in the main chain. ${ }^{4}$ The molecular weight $\left(\bar{M}_{n}=1500\right.$ 3200 ) of these polymers obtained from 2phenyl-3-vinyloxirane derivatives 1 is comparatively low. ${ }^{2,4}$ Vinyloxiranes giving polymers with higher molecular weight have not been reported so far.

In this paper, we report that the radical ringopening polymerization of fluorinated phenyl3-vinyloxirane derivatives $(\mathbf{3}-\mathbf{5})$ can lead to the formation of higher molecular weight polymers having a vinyl ether moiety, whereas chlorinated phenyl-3-vinyloxirane derivatives (1e and 2) afford polymers with low molecular weight under the same polymerization conditions.
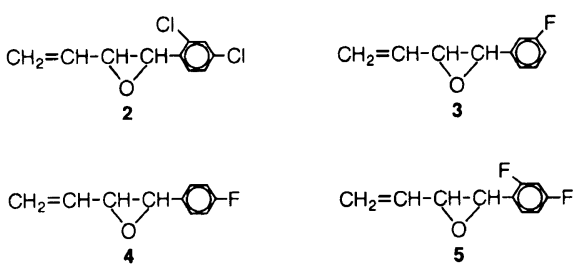

Monomers 2-5

* To whom correspondence should be addressed. 


\section{EXPERIMENTAL}

Synthesis of 2-(m-Fluorophenyl)-3-vinyloxirane

(3)

A mixture of allyl bromide $(13.7 \mathrm{~g}, 0.11 \mathrm{~mol})$ and dimethylsulfide $(7.8 \mathrm{~g}, 0.13 \mathrm{~mol})$ in $10 \mathrm{ml}$ of water was stirred at room temperature overnight. After removal of unreacted dimethyl sulfide at reduced pressure, $m$-fluorobenzaldehyde $(11.9 \mathrm{~g}, 0.10 \mathrm{~mol})$ in $10 \mathrm{ml}$ of isopropyl alcohol was added to the aqueous solution containing allyldimethylsulfonium bromide and subsequently sodium hydroxide $(4.5 \mathrm{~g}, 0.11$ $\mathrm{mol}$ ) in $10 \mathrm{ml}$ of water was added dropwise at room temperature while stirring vigorously. After stirring for 6 hours, the resulting dimethyl sulfide was removed and the solution was extracted with ether three times. The combined organic layer was washed successively with water and brine and dried over anhydrous magnesium sulfate. After removal of ether, the residue was distilled in vacuo to obtain $9.8 \mathrm{~g}$ (yield $62 \%$ ) of 2-( $m$-fluorophenyl)3-vinyloxirane 3: bp $89-91^{\circ} \mathrm{C} / 9 \mathrm{mmHg}$. IR (neat): $3090,2990,1645,1620,1595,1495$, 1230, 990, 930, 890, $865 \mathrm{~cm}^{-1} .{ }^{1} \mathrm{H}$ NMR $\left(\mathrm{CDCl}_{3}\right): 3.23-4.31(2 \mathrm{H}, \mathrm{m}), 5.14-6.00(3 \mathrm{H}$, $\mathrm{m}), 6.83-7.57(5 \mathrm{H}, \mathrm{m}) \mathrm{ppm} .{ }^{13} \mathrm{C}$ NMR $\left(\mathrm{CDCl}_{3}\right)$ : 58.08, 58.18, 59.48, 59.59, 62.79, $112.79,114.09,115.01,115.50,119.67,121.34$, $122.00,129.48,129.75,130.13,131.54,134.62$, $139.66,139.99,157.21,157.59,168.56,168.48$ ppm. Anal. Calcd for $\mathrm{C}_{10} \mathrm{H}_{9} \mathrm{FO}$ : C, $73.16 \%$; $\mathrm{H}, 5.53 \%$. Found: C, $73.06 \%$; H, 5.72\%.

Synthesis of 2-(p-Fluorophenyl)-3-vinyloxirane (4)

4 was synthesized similarly to 3 as mentioned above, bp $54-56^{\circ} \mathrm{C} / 0.5 \mathrm{mmHg}$; yield $74 \%$. IR (neat): 3090, 2990, 1645, 1610, 1515, 1290, 1225, 990, 930, 880, $835 \mathrm{~cm}^{-1}$. ${ }^{1} \mathrm{H}$ NMR $\left(\mathrm{CDCl}_{3}\right): 3.20-4.26(2 \mathrm{H}, \mathrm{m}), 5.14-5.97(3 \mathrm{H}$, $\mathrm{m}), 6.86-7.57(4 \mathrm{H}, \mathrm{m})$ ppm. ${ }^{13} \mathrm{C}$ NMR $\left(\mathrm{CDCl}_{3}\right): 58.13,59.54,62.68,114.52,114.90$, $115.50,115.88,119.45,121.78,126.93,127.26$, $127.85,128.18,130.78,131.75,132.84,134.79$,
156.84, 157.21, $167.78 \mathrm{ppm}$. Anal. Calcd for $\mathrm{C}_{10} \mathrm{H}_{9} \mathrm{FO}: \mathrm{C}, 73.16 \%$; H, 5.53\%. Found: $\mathrm{C}$, $72.91 \% ; \mathrm{H}, 5.80 \%$.

Synthesis of 2-(o,p-Difluorophenyl)-3-vinyloxirane (5)

5 was synthesized similarly to 3 as mentioned above, bp $84-85^{\circ} \mathrm{C} / 9 \mathrm{mmHg}$; yield $67 \%$. IR (neat): 3090, 2990, 1620, 1510, 1285, 1230, 985, 965, 930, $875 \mathrm{~cm}^{-1} .{ }^{1} \mathrm{H}$ NMR $\left(\mathrm{CDCl}_{3}\right)$ : $3.20-4.40(2 \mathrm{H}, \mathrm{m}), 5.17-6.06(3 \mathrm{H}, \mathrm{m})$, $6.63-7.51(3 \mathrm{H}, \mathrm{m}) \mathrm{ppm} .{ }^{13} \mathrm{C} \mathrm{NMR}\left(\mathrm{CDCl}_{3}\right)$ : 53.96, 54.12, 54.34, 59.05, 61.92, 102.44, 103.64, $104.77,110.30,111.00,111.11,111.92,119.89$, $121.95,126.93,127.04,128.88,128.99,131.32$, 134.46, 155.53, 157.27, 166.64, $167.72 \mathrm{ppm}$. Anal. Calcd for $\mathrm{C}_{10} \mathrm{H}_{8} \mathrm{~F}_{2} \mathrm{O}: \mathrm{C}, 65.93 \% ; \mathrm{H}$, $4.43 \%$. Found: $\mathrm{C}, 65.79 \%$; $\mathrm{H}, 4.53 \%$.

Synthesis of 2-(o,p-Dichlorophenyl)-3-vinyloxirane (2)

$\mathbf{2}$ was synthesized similarly to $\mathbf{3}$ as mentioned above, bp $73-74^{\circ} \mathrm{C} / 2 \mathrm{mmHg}$; yield $46 \%$. IR (neat): 3090, 2990, 1645, 1595, 1475, 1380, 1240, 985, 930, $880 \mathrm{~cm}^{-1} .{ }^{1} \mathrm{H}$ NMR $\left(\mathrm{CDCl}_{3}\right)$ : $3.11-4.34(2 \mathrm{H}, \mathrm{m}), 5.06-6.03(3 \mathrm{H}, \mathrm{m})$, $7.11-7.46(3 \mathrm{H}, \mathrm{m}) \mathrm{ppm} .{ }^{13} \mathrm{C} \mathrm{NMR}\left(\mathrm{CDCl}_{3}\right)$ : $56.94,57.21,59.16,62.14,120.05,121.89$, $126.71,127.31,127.42,128.77,128.88,128.99$, $131.05,131.97,133.59,133.76,134.03,134.30$ ppm. Anal. Calcd for $\mathrm{C}_{10} \mathrm{H}_{8} \mathrm{Cl}_{2} \mathrm{O}: \mathrm{C}, 55.84 \%$; $\mathrm{H}, 3.75 \%$. Found: C, $55.48 \%$; H, 3.74\%.

Synthesis of 2-Phenyl-3-vinyloxirane (1a)

1a was synthesized by the method reported previously. $^{2}$ Yield $76 \%$, bp $67-69^{\circ} \mathrm{C} / 3.5$ mmHg (lit. ${ }^{2} 99-100^{\circ} \mathrm{C} / 16 \mathrm{mmHg}$ ), ${ }^{1} \mathrm{H}$ NMR $\left(\mathrm{CDCl}_{3}\right): 3.25-4.30(2 \mathrm{H}, \mathrm{m}), 5.10-5.80(3 \mathrm{H}$, $\mathrm{m}), 7.10-7.45(5 \mathrm{H}, \mathrm{m}) \mathrm{ppm}$.

Synthesis of 2-(p-Chlorophenyl)-3-vinyloxirane

(1e)

1e was synthesized as previously shown. ${ }^{2}$ Yield $50 \%$, bp $135^{\circ} \mathrm{C} / 15 \mathrm{mmHg}$ (lit. ${ }^{2} 135^{\circ} \mathrm{C} / 15$ $\mathrm{mmHg}),{ }^{1} \mathrm{H}$ NMR $\left(\mathrm{CDCl}_{3}\right): 3.17-4.26(2 \mathrm{H}$, m), $5.11-5.96(3 \mathrm{H}, \mathrm{m}), 7.00-7.43(4 \mathrm{H}, \mathrm{m})$ 
ppm.

Radical Polymerization of 1a, 1e, and 2-5

A typical procedure is as follows: after the monomer (3 $\mathrm{mmol})$, radical initiator $(3 \mathrm{~mol} \%)$, and chlorobenzene $(\mathrm{PhCl})(12 \mathrm{mmol})$ were placed in a glass ampoule, the mixture was degassed and sealed in vacuo. Polymerization was carried out at a set temperature for. 48 hours as shown in Table I. The polymer was isolated by pouring the reaction mixture into methanol. The spectral data of the polymers (Run 9-12 in Table I) are as follows:

Polymer from 2. IR (KBr): 3050, 2920, 1660 , $1385,1350,1195,1080,1045 \mathrm{~cm}^{-1},{ }^{1} \mathrm{H}$ NMR $\left(\mathrm{CDCl}_{3}\right): 1.29-3.00$ (br, $-\mathrm{CH}_{2}-\mathrm{C}=\mathrm{C}-$ ), $3.54-5.43(\mathrm{br},-\mathrm{CH}=\mathrm{C}-\mathrm{O}-$ and $-\mathrm{O}-\mathrm{CH}-$ (Ar)-), 5.50-6.29 (br, $-\mathrm{C}=\mathrm{CH}-\mathrm{O}-), 6.59-$ 8.43 (br, Ar-H) ppm, ${ }^{13} \mathrm{C}$ NMR $\left(\mathrm{CDCl}_{3}\right)$ : $30.61,34.18,78.99,100.66,101.52,127.47$, $128.77,131.97,132.67,133.43,133.54,136.99$, $137.55,145.30,145.46,146.54,146.70,146.81$ ppm.

Polymer from 3. IR (KBr): 3050, 2900, 1665, 1400, 1350, $1060 \mathrm{~cm}^{-1},{ }^{1} \mathrm{H}$ NMR $\left(\mathrm{CDCl}_{3}\right)$ : 1.23-3.00 (br, $-\mathrm{CH}_{2}-\mathrm{C}=\mathrm{C}-$ ), 3.49-5.14 (br, $-\mathrm{CH}=\mathrm{C}-\mathrm{O}-$ and $-\mathrm{O}-\mathrm{CH}(\mathrm{Ar})-), 5.60-6.14$ (br, $-\mathrm{C}=\mathrm{CH}-\mathrm{O}-$ ), 6.29-8.22 (br, Ar-H) ppm, ${ }^{13} \mathrm{C} \mathrm{NMR}\left(\mathrm{CDCl}_{3}\right): 32.13,35.86,79.53,80.88$, $82.67,101.20,101.69,112.63,112.74,113.71$, $114.74,121.19,121.95,129.53,129.80,143.94$, $144.32,145.03,145.30,157.27,168.16 \mathrm{ppm}$.

Polymer from 4. IR (KBr): 3050, 2900, 1660, $1350,1060 \mathrm{~cm}^{-1},{ }^{1} \mathrm{H}$ NMR $\left(\mathrm{CDCl}_{3}\right): 1.20$ 3.03 (br, $-\mathrm{CH}_{2}-\mathrm{C}=\mathrm{C}-$ ),$\quad 3.40-5.20$ (br, $-\mathrm{CH}=\mathrm{C}-\mathrm{O}-$ and $-\mathrm{O}-\mathrm{CH}(\mathrm{Ar})-$ ), 5.45-6.11 (br, $-\mathrm{C}=\mathrm{CH}-\mathrm{O}-$ ), 6.29-8.29 (br, Ar-H) ppm, ${ }^{13} \mathrm{C}$ NMR $\left(\mathrm{CDCl}_{3}\right): 32.40,36.19,37.54,38.63$, $56.99,63.49,101.36,101.74,114.69,115.23$, $115.66,128.01,128.34,136.79,137.49,145.51$, 146.76, 156.84, $167.78 \mathrm{ppm}$.

Polymer from 5. IR (KBr): 3060, 2920, 1660 , $1360,1060 \mathrm{~cm}^{-1},{ }^{1} \mathrm{H}$ NMR $\left(\mathrm{CDCl}_{3}\right): 1.26$ 3.14 (br, $-\mathrm{CH}_{2}-\mathrm{C}=\mathrm{C}-$ ), 3.49-5.39 (br, $-\mathrm{CH}=\mathrm{C}-\mathrm{O}-$ and $-\mathrm{O}-\mathrm{CH}(\mathrm{Ar})-)$, 5.57-6.09 (br, $-\mathrm{C}=\mathrm{CH}-\mathrm{O}-$ ), $6.17-8.14$ (Ar-H) ppm,
${ }^{13} \mathrm{C} \mathrm{NMR}\left(\mathrm{CDCl}_{3}\right): 31.04,34.56,74.22,76.17$, 101.47, 103.26, 104.39, 104.50, 110.68, 111.55, $123.52,128.72,145.04,156.35,156.84,164.85$, $167.78 \mathrm{ppm}$.

\section{RESULTS AND DISCUSSION}

Halogenated phenyl-3-vinyloxiranes (2-5) were synthesized in good yields as reported previously. $^{2}$

Radical polymerizations of vinyloxiranes 2-5 were carried out in $\mathrm{PhCl}$ or bulk for 48 hours in the presence of azobisisobutyronitrile (AIBN) or di- $t$-butylperoxide (DTBP) (3 mol\% for vinyloxirane) in sealed tube. Radical polymerizations of 1a $(\mathrm{X}=\mathrm{H})$ and $1 \mathrm{e}(\mathrm{X}=\mathrm{Cl})$ were also performed under the same conditions for comparison with the results of $\mathbf{2}-\mathbf{5}$. The polymers were isolated by pouring the reaction mixture into methanol. The results are summarized in Table I. 1a and chlorinated phenyl-3-vinyloxiranes $1 \mathrm{e}$ and $\mathbf{2}$ gave the corresponding polymers with molecular weights $\left(\bar{M}_{n}\right) 2400-3400$ by polymerization in bulk at $60^{\circ} \mathrm{C}$ (Runs $1-3$ ). The molecular weight of the polymer obtained from 2-( $m$-fluorophenyl)-3vinyloxirane 3 was essentially the same as that of the polymer from 1a (Run 4), whereas 4 and 5 gave polymers with molecular weights twice those of the polymers obtained from 1a, 1e, 2, and 3 in polymerization in bulk at $60^{\circ} \mathrm{C}$ (Runs 5 and 6$)$.

The radical polymerizations of $\mathbf{1 a}, \mathbf{1 e}$, and 2-5 were also carried out in $\mathrm{PhCl}$ at $120^{\circ} \mathrm{C}$ to afford the corresponding polymers having a vinyl ether moiety in the backbone via cleavage of the carbon-carbon bond of the oxirane ring. The molecular weights of the polymers obtained from fluorinated phenyl-3-vinyloxiranes $3-5$ were higher than those obtained from 1a, 1e, and 2. 2-( $p$-Fluorophenyl)-3-vinyloxirane 4 afforded the polymer with high molecular weight $\left(\bar{M}_{n}=11800\right)$ (Run 11). The polymer obtained from 2-( $p$-chlorophenyl)-3-vinyloxirane 1e had lower molecular weight $\left(\bar{M}_{n}=3200\right)$ (Run 8). The same was observed in the radical 
polymerization of 2-(o,p-difluorophenyl)-3vinyloxirane 5 and 2-(o,p-dichlorophenyl)-3vinyloxirane 2 . The molecular weights of the polymers obtained from 5 and 2 were 9300 and 1600, respectively (Runs 9 and 12). The polymer obtained from 4 bearing a fluorine atom at $p$-position had higher molecular weight than that from 3 bearing a fluorine atom at $m$-position (Runs 10 and 11). In a comparison of the radical polymerizations of $\mathbf{1 a}, \mathbf{1 e}$, and 2, molecular weights of the polymers decreased in the following order: $\mathbf{1 a}>\mathbf{1 e}>\mathbf{2}$ (Runs 7-9). Thus, fluorinated phenyl-3-vinyloxiranes 3-5 gave higher molecular weight polymers than $\mathbf{1 a}$ and chlorinated phenyl-3-vinyloxiranes 1e and 2.

The structures of the obtained polymers were confirmed by IR and ${ }^{1} \mathrm{H}$ NMR spectra. Cho et al. reported that the structure of the polymer from 1a was confirmed by IR and ${ }^{1} \mathrm{H}$ NMR by a comparison with that of a model compound obtained by the radical addition of benzenethiol to 1a. IR and ${ }^{1} \mathrm{H}$ NMR data of the model compound were compatible with those of polymers from $1 \mathrm{e}$ and $2-5$. In the IR spectra of the starting vinyloxiranes and the obtained polymers, absorption around 880 $\mathrm{cm}^{-1}$ due to the oxirane disappeared completely and absorption around $1660 \mathrm{~cm}^{-1}$ due to the vinyl ether group was observed after rad- ical polymerization. All ${ }^{1} \mathrm{H}$ NMR spectra of the polymers were very similar to that of the polymer from 1a, and showed very broad signals at ca. 1.3-3.0 $\left(-\mathrm{CH}_{2}-\mathrm{C}=\mathrm{C}-\right), 3.5-$ $5.4(-\mathrm{CH}=\mathrm{C}-\mathrm{O}-$ and $-\mathrm{O}-\mathrm{CH}(\mathrm{Ar})-), 5.5-6.2$ $(-\mathrm{C}=\mathrm{CH}-\mathrm{O}-)$, and $6.3-8.2(\mathrm{Ar}-\mathrm{H})$, respectively. ${ }^{13} \mathrm{C}$ NMR spectra of the polymers from 1a, 1e, and $3-5$ showed that signals around $54.0-63.0$ corresponding to the oxirane carbons disappeared completely. These spectral data give indication that the radical ringopening polymerizations (1,5-polymerization) of $1 \mathrm{a}, \mathbf{1 e}$, and $3-5$ proceed through cleavage of the carbon-carbon bond of the oxirane as also reported by Cho et al. ${ }^{3}$ and Endo et al..$^{2,4}$ In the ${ }^{13} \mathrm{C} \mathrm{NMR}$ of the polymer from 2 , very small signals $(56.99,57.21$, and $59.21 \mathrm{ppm})$ possibly due to the oxirane carbons were observed. The radical polymerization of $\mathbf{2}$ would thus appear to be 1,5-polymerization accompanied by a small amount of 1,2polymerization (vinyl polymerization).

The reason why 3 and 4 lead to the formation of the polymer with higher molecular weight is not clear at present. In the radical polymerizations of $p$-substituted styrenes, the rate constant $\left(k_{\mathrm{p}}\right)$ for propagation increases as the Hammett substituent constant $\left(\sigma_{\mathrm{p}}\right)$ increases $\quad\left[k_{\mathrm{p}}: \quad \mathrm{H}<\mathrm{F} \quad\left(\sigma_{\mathrm{p}}=0.062\right)<\mathrm{Cl} \quad\left(\sigma_{\mathrm{p}}=\right.\right.$ $\left.0.227)<\operatorname{Br}\left(\sigma_{\mathrm{p}}=0.232\right)\right]$ and the rate constant

Table I. Radical polymerizations of 1a, 1e, and $2-5$

\begin{tabular}{rccccccc}
\hline Run & Oxirane & Solvent & Initiator & Temp $/{ }^{\circ} \mathrm{C}$ & Yield $/ \%^{\mathrm{a}}$ & $\bar{M}_{n}{ }^{\mathrm{b}}$ & $\bar{M}_{w} / \overline{\boldsymbol{M}}_{n}^{\mathrm{b}}$ \\
\hline 1 & $\mathbf{1 a}$ & Bulk & AIBN & 60 & 10 & 3400 & 1.84 \\
2 & $\mathbf{1 e}$ & Bulk & AIBN & 60 & 12 & 2800 & 1.81 \\
3 & $\mathbf{2}$ & Bulk & AIBN & 60 & 14 & 2400 & 2.25 \\
4 & $\mathbf{3}$ & Bulk & AIBN & 60 & 8 & 3400 & 1.65 \\
5 & $\mathbf{4}$ & Bulk & AIBN & 60 & 11 & 6100 & 1.67 \\
6 & $\mathbf{5}$ & Bulk & AIBN & 60 & 10 & 6600 & 1.65 \\
7 & $\mathbf{P h C l}$ & DTBP & 120 & 36 & 4200 & 7.91 \\
8 & $\mathbf{1 a}$ & $\mathrm{PhCl}$ & DTBP & 120 & 32 & 3200 & 3.07 \\
9 & $\mathbf{2}$ & $\mathrm{PhCl}$ & DTBP & 120 & 29 & 1600 & 2.61 \\
10 & $\mathbf{3}$ & $\mathrm{PhCl}$ & DTBP & 120 & 32 & 6800 & 2.81 \\
11 & $\mathbf{4}$ & $\mathrm{PhCl}$ & DTBP & 120 & 43 & 11800 & 8.70 \\
12 & $\mathbf{5}$ & $\mathrm{PhCl}$ & DTBP & 120 & 39 & 9300 & 3.68 \\
\hline
\end{tabular}

${ }^{a}$ Insoluble in $\mathrm{MeOH} .{ }^{b}$ Estimated by GPC (based on PSt). 
$\left(k_{\mathrm{t}}\right)$ for termination increases in the following order: $\mathrm{Br}<\mathrm{Cl}<\mathrm{H}<\mathrm{F}^{5}$ The molecular weights of the polymers obtained from $1 \mathbf{a}(p-\mathrm{H})$, 1e $(p-\mathrm{Cl})$, and $4(p-\mathrm{F})$ increased as $k_{\mathrm{t}}$ increased (Runs 1, 2, 4, 7, 8, and 11). It is reported that propagating radicals from styrene and $p$ chlorostyrene terminate entirely by coupling. ${ }^{6,7}$ The mode of termination may be coupling in the polymerization of vinyloxiranes, since the propagating radicals (benzyl radical) from vinyloxiranes are the same as those from styrenes. It is assumed that differences in $k_{\mathrm{t}}$ may cause different results in the radical polymerizations of $\mathbf{1 a}, \mathbf{1 e}$, and $\mathbf{2}-\mathbf{5}$. Also the electronic effect of fluorine atom presumably may possibly lead to easy cleavage of the carbon-carbon bond of the oxirane ring and inhibit side reactions such as chain transfer, since 4 and 5 having weak electron-withdrawing group $\left(\mathrm{F}: \sigma_{\mathrm{p}}=0.026\right)$ gave higher molecular weight polymers than $\mathbf{1 e}, \mathbf{2}$, and 3 having strong electron-withdrawing group $(\mathrm{F}$ : $\sigma_{\mathrm{m}}=0.337, \mathrm{Cl}: \sigma_{\mathrm{p}}=0.227$ ) except for $1 \mathrm{a}$.

\section{REFERENCES}

1. (a) T. Endo and T. Yokozawa, "New Methods for Polymer Synthesis,” W. J. Mijis, Ed., Plenum Press, New York, 1992, p 155; (b) W. J. Bailey, P. Y. Chen, S.-C. Chen, W.-B. Chiao, T. Endo, B. Gapud, V. Kuruganti, Y.-N. Lin, Z. Ni, C.-Y. Pan, S. E. Shaffer, L. Sidney, S.-R. Wu, N. Yamamoto, N. Yamazaki, K. Yonezawa, and L.-L. Zhou, Makromol. Chem., Macromol. Symp., 6, 81 (1986).

2. T. Endo and N. Kanda, J. Polym. Sci., Polym. Chem. Ed., 23, 1931 (1985).

3. I. Cho and J.-B. Kim, J. Polym. Sci., Polym. Lett. Ed., 21, 433 (1983).

4. T. Koizumi, Y. Nojima, and T. Endo, J. Polym. Sci., Polym. Chem. Ed., 31, 3489 (1993).

5. M. Imoto, M. Kinoshita, and M. Nishigaki, Macromol. Chem., 86, 212 (1965).

6. J. C. Bevington and H. W. Melville, J. Polym. Sci., 12, 449 (1952).

7. G. Ayrey, F. G. Levitt, and R. J. Mazza, Polymer, 6, 157 (1965). 